\title{
Usos e Jogos de Linguagem na Matemática: Diálogo entre Filosofia e Educação Matemática
}

\author{
Ricardo José Reis de Abreu \\ Daniel Santini Rodrigues
}

\begin{abstract}
VILELA, Denise Silva. Usos e Jogos de Linguagem na Matemática: Diálogo entre Filosofia e Educação Matemática. 1. ed. São Paulo: Editora Livraria da Física, 2013.
\end{abstract}

Esta obra tem origem na tese de doutorado realizado pela pesquisadora em Educação Matemática, Denise Silva Vilela, na Faculdade de Educação da UNICAMP. Atualmente a Educação Matemática está consolidada como um campo fértil de pesquisas inclusive a nível internacional. Vilela organizou a referida obra em quatro seções.

Neste trabalho, Vilela chama a atenção para a interação entre a Matemática e as Ciências Humanas que passam a constituir um novo campo do saber que tem seu início marcado por uma relação de subordinação da Educação Matemática em relação à matemática. Suas referências são os usos (adjetivações) que têm sido feitos da expressão matemática por educadores matemáticos, onde ela busca analisá-los através de uma perspectiva filosófica pós-crítica, lançando outro olhar sobre as discussões que envolvem as diferentes concepções da matemática, dissolvendo imagens exclusivistas e privilegiadas, tomando como objeto de estudos publicações e pesquisas acadêmicas recentes em Educação Matemática, mas sem a pretensão de fazer indicações do que é certo ou errado, sem a intenção de se aproximar das verdades absolutas, mas de buscar outras maneiras de ver e pensar, conforme sugere a filosofia de Wittgenstein.

Sendo assim, a primeira seção da obra intitulada "A proposta de ampliação dos significados e a terapia filosófica de Wittgenstein" chama atenção para a produção matemática totalmente desconexa com as realidades e saberes locais, conforme estudos de pesquisadores em Etnomatemática que reivindicam abordagens específicas a cada grupo cultural em detrimento de currículos prontos e generalizados. Neste contexto, a autora insere a Etnomatemática em uma perspectiva da filosofia pós-guinada linguística, negando à matemática características como exatidão, neutralidade, essência e verdade única. A partir daí, Vilela passa a observar os usos da expressão matemática no âmbito da Educação Matemática em seus diversos modos de adjetivação, buscando explicar esse processo de multiplicação das adjetivações não como fragmentação do saber em Educação Matemática, mas como um processo de diversificação e ampliação dos significados baseado na filosofia de Wittgenstein, considerada um marco na guinada linguística e frequentemente associada a um movimento de desconstrução da universalidade e eternidade dos fundamentos do conhecimento. Nessa perspectiva, os significados são variáveis conforme os jogos de linguagem dos quais participam, já que "ao buscar um sentido fora do contexto de uso ou de um jogo de linguagem, a tendência é buscar um sentido absoluto, uma essência” (p. 32, grifo nosso).

Nesse sentido, a autora busca desfazer essa imagem exclusivista da matemática produtora de verdades inquestionáveis que sempre impedem de enxergar outras matemáticas. Para desconstruir essa imagem exclusivista de ciência superior, neutra e única da matemática, ela sugere como exercício a terapia filosófica, não como um conjunto de regras que aponte erros e soluções, mas com uma perspectiva de ampliação dos significados e compreensão da matemática como prática social. Também não se trata de substituir uma metanarrativa por outra, mas de abandonar a ideia de uma matemática independente. "A verdade e o erro são próprios não da filosofia, mas do senso comum em que as pessoas precisam de tranquilidade e segurança” (p. 43).

$\mathrm{Na}$ segunda seção, cujo título é "Análise interpretativa das adjetivações", Vilela apresenta sua metodologia de pesquisa tomando como base trabalhos acadêmicos produzidos na área de Educação Matemática a nível nacional nas últimas três décadas. A autora constata uma predominância de expressões adjetivadas na forma de pares tensionais, bipolarizados, tais como matemática escolar e matemática da rua, matemática escolar e matemática de um grupo profissional específico, matemática oral e matemática escrita, dentre muitos outros.

A partir das análises desses textos, Vilela constata algumas especificidades entre as práticas 
matemáticas percebidas por pesquisadores tais como Plínio Cavalcanti Moreira e Maria Manuela Martins Soares David, Alexandrina Monteiro, Terezinha Nunes Carraher, Rômulo Campos Lins e Joaquim Gimenez, dentre outros. Essas matemáticas adjetivadas colocadas ao lado de seus pares tensionais são analisadas interpretativamente como jogos de linguagem, porém sem nenhuma pretensão de crítica e sim de reconhecimento do valor dessas pesquisas no campo da Educação Matemática.

O que mais fica claro nas análises dos textos trazidos pela autora é a legitimidade de se interpretar as matemáticas adjetivadas como jogos de linguagem e uma tendência de abandono da referência de uma matemática ideal e eurocêntrica em favor das práticas matemáticas culturalmente identificadas. Dessa forma, a autora se serve das reflexões filosóficas e sociológicas para problematizar a questão e aprofundar a temática da Educação Matemática. As duas seções seguintes da obra abordam a temática nestes dois olhares: o filosófico e o sociológico.

$\mathrm{Na}$ terceira seção, intitulada "Um sentido filosófico das adjetivações: diferentes jogos de linguagem", Vilela interpretou, à luz das investigações de Wittgenstein, que as adjetivações expressam diferentes jogos de linguagem e muitas vezes não se referem a uma matemática única, referencial e independente das práticas. As noções de Wittgenstein de jogos de linguagem, regras $e$ formas de vida compuseram o modelo teórico usado para analisar os documentos de pesquisa. Por isso, a autora esclarece a compreensão destas noções, que são fundamentais para entender as problematizações futuras. Contrapondo às concepções platônica e empirista da matemática, segundo as quais sustentam a noção de matemática neutra e verdadeira, Vilela explica que se pode fazer diversos usos de uma mesma palavra, ou seja, uma palavra pode ser usada com significados muito diferentes em situações diferentes. "Wittgenstein remete o significado das palavras aos jogos de linguagem e também compara a própria linguagem a um jogo" (p. 185). Dessa forma, ele enfatiza a natureza heterogênea, a diversidade de suas funções e a variedade de usos possíveis da linguagem e dos significados das palavras. Ou seja, as diversas práticas matemáticas (matemática escolar, matemática de rua, matemática acadêmica, matemática popular, matemática do cotidiano, etc.) "podem ser interpretadas como participando de diferentes jogos de linguagem e, portanto, seus significados não convergem. Mantêm, no máximo, como diria Wittgenstein, uma semelhança de família". (p. 189). Elas mantêm uma complexa rede de semelhanças que se sobrepõem e se entrecruzam, do mesmo modo que os membros de uma família se parecem uns com os outros sob diferentes aspectos.

A autoria conclui, dentro desta perspectiva de Wittgenstein, que "conhecer uma matemática depende de conhecer qual é o jogo". (p. 192). Mas para isso, precisa-se conhecer as regras definidas pelas formas de vida instauradora desse jogo. $\mathrm{O}$ uso das regras é especificado nos jogos de linguagem. Segundo Vilela, age-se em conformidade com as regras e não obrigados por ela. (p. 197), sendo que uma regra se apresenta como um indicador de direção. Dessa forma, os significados "são direcionados pela gramática - complexo de regras da linguagem - e condicionados por formas de vida, mas não preestabelecidos definitiva $\mathrm{e}$ universalmente". (p. 198). Assim, a gramática indica as regras de uso das palavras, o que faz sentido e o que é certo ou errado. Além disso, segundo Vilela, a gramática se funda em formas de vida, que, por sua vez, são cristalizações de experiências que dependem do mundo, ou de acordos comunitários ou de ideias públicas. As regras da gramática estão sujeitas a mudanças, propiciando um aspecto dinâmico na linguagem, pois "são as práticas comuns de usos que geram as regras da gramática" (p. 205). A gramática se estabelece pautada em forma de vida. Sendo assim, a "ideia de uma matemática necessária e única pode ser vista como um tipo de confusão gramatical". (p. 213). As confusões são causadas também por se alimentar concepções estreitas do significado de palavras nas quais se fixa a atenção num significado específico ou alimentar um tipo específico de funcionamento da palavra. Dentre suas principais causas estão a analogia e a dieta unilateral. (p. 218219). Diante dessas confusões gramaticais, Vilela constata que, a partir da Educação Matemática, surgiu a necessidade de alimentar outras imagens de matemática. Assim, Vilela mostra que a filosofia de Wittgenstein possibilita uma leitura coerente das adjetivações produzidas no terreno acadêmico da Educação Matemática.

Com base nos estudos de David Bloor e S. Restivo, a autora traz as contribuições da Sociologia da Ciência para "mostrar que o conhecimento científico é uma construção social, tanto porque são construídos por grupos de cientistas em interação, como também porque os interesses sociais afetam o desenvolvimento e a avaliação das teorias e técnicas". (p. 229). Para aprofundar esta temática, 
na quarta seção de sua obra, com o título "Um sentido sociológico para as adjetivações: tensão no campo da Matemática", a autora elabora novas questões de pesquisa: "qual o sentido sociológico das adjetivações? $O$ que as adjetivações expressariam se tomamos o referencial das ciências sociais e não o da filosofia?" (p. 231). Para problematizar esta reflexão, Vilela foca em autores da década de 1980/1990 para pensar as adjetivações como tensões no campo da matemática.

Tanto Bloor quanto Restivo discutem a crença de ser a matemática um conhecimento social e relativo a algo social. "Ambos falam a partir da sociologia do conhecimento e tomam de Durkheim a relação entre lógica e religião" (p. 233). Esta relação está clara, segundo Durkheim, no fato da matemática se alienar do que produz, a exemplo da religião. Ou seja, a construção de uma realidade separada e autônoma pode criar a sensação de que os objetos matemáticos não dependem do matemático. Além disso, a ideia de pureza na matemática "vai se construindo a partir do seu distanciamento em relação a situações da vida cotidiana, pela abstração e pela linguagem" (p. 249).

Restivo baseia-se suas argumentações no conceito de representação coletiva, de Durkheim. Tal conceito traz no cerne a força das ideias partilhadas/coletivas que carregam relações sociais e históricas em detrimento de escolhas, desejos e pensamentos individuais, ou seja, não aparece a intencionalidade dos agentes. Segundo Vilela (p. 260), "a abordagem de Restivo ajuda a compreender a crença hegemônica na unicidade da matemática, através dos processos humanos e sociais de classificação, alienação, generalização e universalização".

Diante disso, a autora busca na Teoria da Prática de Bourdieu a discussão sobre a mediação entre o individual e o coletivo no âmbito das perspectivas sociológica, fenomenológica e objetivista. Ou seja, a solução seria encontrar uma mediação entre o homem e a história, entre o agente social e a sociedade. Com esta teoria, Bourdieu quer introduzir nas Ciências Sociais uma teoria do sujeito da ação. A abordagem de Bourdieu implica num duplo desdobramento para o tema em discussão nesta pesquisa de Vilela: sua teoria da prática condicionará a base para a compreensão das matemáticas como práticas sociais e as consequências sociais das posições metafísicas. Para associar a Teoria da Prática à sociologia da ciência,
Bourdieu apresenta a noção de campo científico, que pode ser entendido como "o lócus onde se trava a luta entre atores em termos de interesses específicos, ou seja, situações em que se manifestam as relações de poder em torno da autoridade ou legitimidade". (p. 276). Segundo Denise (p. 279), a noção de campo científico auxilia na compreensão do tema das adjetivações.

Diante de todas estas fundamentações e problematizações, Vilela aponta, em alguns textos relativos à etnomatemática, uma postura conciliatória com a matemática acadêmica: "não se trata de um confronto da matemática acadêmica versus a etnomatemática, mas uma completando a outra num crescimento simultâneo. A sala de aula passa a ser um ponto de troca de conhecimentos entre as duas posturas de uma mesma ciência". (Costa apud VILELA, p. 286).

A autora encerra a quarta seção da obra deixando em aberto a seguinte questão: "a objetivação de novos termos na gramática, como 'matemática escolar', estariam apontando para uma transformação no campo da matemática?” (p. 294).

Por fim, em suas considerações finais, cujo título é "Desdobramentos de uma terapêutica Wittgensteiniana", Vilela reafirma a inspiração inicial de sua pesquisa que foi a possibilidade de constituir uma base filosófica para a etnomatemática. Ela constata que a filosofia de Wittgenstein se "mostrou fértil para a interpretação das adjetivações do termo matemática na literatura acadêmica da Educação Matemática e chegou a superar as expectativas em sua potencialidade de explicar, elucidar e ampliar concepções" (p. 295). A autora destaca diversas contribuições desta perspectiva filosófica na análise da questão de pesquisa.

Portanto, a autora quer abrir a questão para futuras reflexões e problematizações, mas observa com esperança o fato de outras práticas matemáticas começarem a ser reconhecidas como produtoras de conhecimentos, e estão sendo pesquisadas com o intuito de participarem de programas curriculares em oposição a um programa de matemática idêntico em todas as escolas.

Esta obra é de grande valia para se problematizar a presença na matemática na escola, porém uma presença que resguarde a pluralidade e a diversidade da matemática. Não uma única matemática, mas práticas matemáticas em suas diferentes concepções. 